\title{
Review of VA/DOD Clinical Practice Guideline on management of acute stress and interventions to prevent posttraumatic stress disorder
}

\author{
William P. Nash, MD; ${ }^{1}$ Patricia J. Watson, PhD $^{2 *}$ \\ ${ }^{1}$ Department of Psychiatry, University of California, San Diego, San Diego, CA; ${ }^{2}$ National Center for PTSD, White River \\ Junction, VT; National Center for Child Traumatic Stress, Los Angeles, CA; and Dartmouth Medical School, Hanover, NH
}

\begin{abstract}
This article summarizes the recommendations of the Department of Veterans Affairs (VA)/Department of Defense (DOD) VA/DOD Clinical Practice Guideline for Management of Post-Traumatic Stress that pertain to acute stress and the prevention of posttraumatic stress disorder, including screening and early interventions for acute stress states in various settings. Recommended interventions during the first 4 days after a potentially traumatic event include attending to safety and basic needs and providing access to physical, emotional, and social resources. Psychological first aid is recommended for management of acute stress, while psychological debriefing is discouraged. Further medical and psychiatric assessment and provision of brief, trauma-focused cognitive-behavioral therapy are warranted if clinically significant distress or functional impairment persists or worsens after 2 days or if the criteria for a diagnosis of acute stress disorder are met. Follow-up monitoring and rescreening are endorsed for at least 6 months for everyone who experiences significant acute posttraumatic stress. Four interventions that illustrate early intervention principles contained in the VA/DOD Clinical Practice Guideline are described.
\end{abstract}

Key words: acute stress disorder, acute stress response, clinical practice guideline, combat and operational stress response, crisis intervention, early intervention, military, psychological first aid, PTSD, veterans.

\section{INTRODUCTION}

The newly revised Department of Veterans Affairs (VA)/Department of Defense (DOD) VA/DOD Clinical
Practice Guideline for Management of Post-Traumatic $\underline{\text { Stress, }}$ published October 2010 [1], draws greater attention than its predecessor to the challenge of promoting prevention of posttraumatic stress disorder (PTSD) and other adverse outcomes of exposure to traumatic stress in servicemembers, veterans, and their families. The entire Core Module of the CPG is now devoted to reviewing concepts and evidence-informed actions for prevention in three domains: promoting primary prevention through education and training (pre-exposure), identifying high-risk populations

\footnotetext{
Abbreviations: $\mathrm{ASD}=$ acute stress disorder; $\mathrm{ASR}=$ acute stress reaction; $\mathrm{CBT}=$ cognitive-behavioral therapy; $\mathrm{COSFA}=$ Combat and Operational Stress First Aid; COSR = combat and operational stress reaction; CPG = Clinical Practice Guideline; DOD = Department of Defense; DSM = Diagnostic and Statistical Manual of Mental Disorders; DSM-IV = DSM, 4th Edition; FOCUS = Families Overcoming Under Stress; ICD-10 = International Classification of Diseases, 10th Edition; IOM = Institute of Medicine; NCPTSD = National Center for PTSD; NCTSN = National Child Traumatic Stress Network; NRC = National Research Council; PD = psychological debriefing; PFA = psychological first aid; PTSD = posttraumatic stress disorder; SPR = Skills for Psychological Recovery; VA = Department of Veterans Affairs.

*Address all correspondence to Patricia J. Watson, PhD; National Center for PTSD-Executive Division, VA Regional Medical Center, 215 N. Main St, White River Junction, VT 05009; 808-756-7259; fax: 802-295-5135.
}

Email: patricia.j.watson@dartmouth.edu http://dx.doi.org/10.1682/JRRD.2011.10.0194 
based on the nature of traumatic events and other stressors (peri-exposure), and implementing the secondary prevention action of screening for significant trauma-related symptoms so that appropriate early interventions can be undertaken (postexposure). Module A, which immediately follows the Core Module, now provides detailed guidance on specific evidence-informed early interventions to promote recovery from both preclinical acute stress reactions (ASRs) and acute stress disorder (ASD), a possible clinical precursor of PTSD.

As we enter the second decade of war in Afghanistan and Iraq and the rolls of physical and psychological casualties continue to grow, the prevention of PTSD, suicide, violence, substance abuse, and other serious behavioral sequelae of war-zone stress have become a national mandate [2-3]. Over the past few years-since the first VA/ DOD Clinical Practice Guideline (CPG) for management of post-traumatic stress was released in 2004—countless new programs for prevention and resilience-building have been funded and launched in the VA, DOD, and military service branches, including their Active, Reserve, and National Guard components [4]. Besides being great in number, these new prevention programs for military personnel, veterans, and their families are highly diverse in their approaches. Some focus on pre-exposure education, training, and other interventions to promote resilience through multidomain fitness [5-6], while others provide tools for screening and early interventions to promote recovery postexposure [7]. Since the absolute and relative effectiveness of these diverse approaches to prevention have not yet been well studied, the value of expert, evidence-informed consensus recommendations such as those contained in the VA/DOD CPG can hardly be overstated.

Like its predecessor, the revised CPG assigns confidence grades to each of its recommendations in three dimensions: level of evidence, quality of evidence, and strength of recommendation (see Appendix, available online only). In general, stronger recommendations in the CPG are based on higher levels and quality of evidence. Where existing literature is lacking, ambiguous, or conflicting, CPG recommendations are based on consensus of the expert working group tasked with writing the CPG. Particularly in the area of prevention, where the literature has not kept pace with the need for effective programs, the CPG at times makes strong recommendations in the absence of randomized controlled trials incorporating the most relevant outcome measures.

\section{METHODS}

We reviewed the sections of the Core Module and Module A of the CPG that specifically address postexposure screening and early interventions for the prevention of PTSD. Included are definitions of the spectrum of preclinical and clinical acute stress states; methods for recognizing them in servicemembers, veterans, and family members; and approaches for early intervention to prevent them from progressing to PTSD and other potentially chronic traumarelated disorders. We compared the approach taken to prevention and early intervention in the CPG to the current framework for classifying prevention interventions developed by the National Research Council (NRC)-Institute of Medicine (IOM) Committee for the Prevention of Mental Disorders. Finally, we briefly reviewed four existing early intervention programs developed by DOD and VA personnel for use both inside and outside VA and DOD settings, that were founded on the concepts and actions described in the CPG.

\section{RESULTS}

\section{National Research Council-Institute of Medicine Mental Health Intervention Framework}

In 1994, the IOM Committee for the Prevention of Mental Disorders recommended a new typology intervention to prevent mental disorders, building on earlier work by Gordon [8], that was based solely on who an intervention targeted without regard for whether the persons receiving a prevention intervention were pre-, peri-, or postexposure to triggering stressor events. The IOM framework defined three levels of prevention: (1) universal interventions, which target entire populations; (2) selective interventions, which target groups or individuals at elevated risk; and (3) indicated interventions, which target individuals with early, preclinical, or subthreshold symptoms or behaviors that are precursors of mental disorders, though not yet diagnosable as such [9]. In 2009, the NRC-IOM Committee on the Prevention of Mental Disorders and Substance Abuse Among Children, Youth, and Young Adults revised the 1994 IOM framework by adding health promotion as a first level of prevention, although by definition, health promotion focuses on increasing levels of health rather than preventing any particular disease [10].

As depicted in Figure 1, the 2009 NRC-IOM framework has direct relevance for PTSD prevention in military 
and VA populations. Current or historical military prevention programs have always been designed to affect either entire populations, subgroups at increased risk, or individuals recognized to be significantly distressed or impaired but not yet clinically diagnosable [11]. The alternative public health framework of primary, secondary, and tertiary prevention can be more challenging to apply to military units whose members typically span the entire spectrum from those who are trauma naïve, those who are yet unexposed to military traumas but are recovering from preservice traumas, those with subthreshold posttraumatic symptoms from a previous deployment or civilian event, and those who are clinically diagnosable with PTSD. Another advantage of the current NRC-IOM framework is that it encourages screening for subthreshold or preclinical posttraumatic stress states, sometimes called traumatic stress injuries, as possibly particularly fruitful targets for early intervention [12].

\section{Spectrum of Posttraumatic Stress States}

Figure 2 is adapted from the algorithm for initial evaluation and triage contained in the Core Module of the CPG, which provides a framework for categorizing posttraumatic stress states based on both duration and severity of distress and functional impairment. Although states of distress or alterations in functioning in the aftermath of exposure to traumatic events naturally fall along a continuum of severity and duration rather than occurring only in discrete, easily discernible categories, the process of assessment and triage described in the CPG is a vital first step before selecting the intervention most likely to be beneficial and least likely to do harm. The CPG recognizes four distinct posttraumatic stress states.

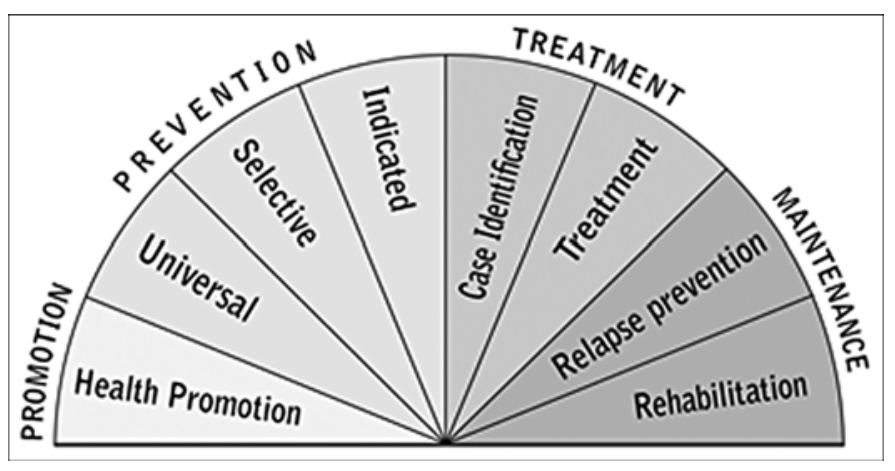

Figure 1.

National Research Council-Institute of Medicine mental health intervention framework.

\section{Acute Stress Reaction}

As depicted in Figure 2, posttraumatic stress may be categorized as ASR if symptoms have existed for less than 4 days, regardless of how severe or disabling those symptoms may have been over that time. The CPG acknowledges that ASR is not included in the Diagnostic and Statistical Manual of Mental Disorders (DSM), 4th Edition (DSM-IV) as a clinical entity, but draws its definition from the World Health Organization's International Classification of Diseases, 10th Edition (ICD-10) Classification of Mental and Behavioral Disorders, which describes ASR as a common but transient condition that usually appears within minutes of a traumatic stressor experience and normally disappears within 2-3 days, often within a few hours. As noted in the Core Module of the ICD-10, ASR symptoms can appear in any domain of experience or functioning, including physical, cognitive, emotional, and behavioral distress or alterations in functioning. The distress and dysfunction that accompany ASR can be profound, even if short-lived. ASR is a crisis state, considered

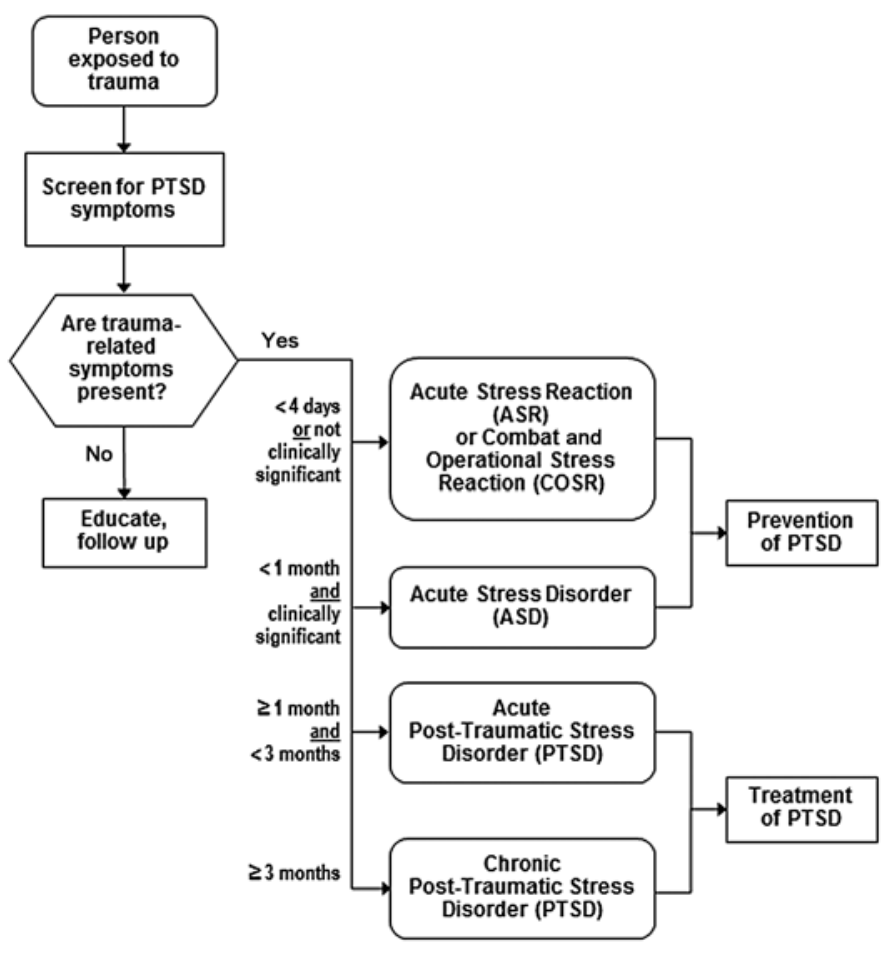

Figure 2.

Algorithm for initial evaluation and triage in Core Module of Clinical Practice Guideline. Provides framework for categorizing posttraumatic stress states based on duration and severity of distress and functional impairment. 
"normal" to the extent that it is predictable and common in the immediate aftermath of a traumatic event and usually resolves without long-term sequelae.

The CPG asserts that peri- or posttraumatic stress constitutes an ASR if it lasts fewer than 4 days, regardless of severity, or if the severity of posttraumatic distress or alterations in functioning remain below the threshold for clinical significance even though they persist beyond 4 days.

\section{Combat and Operational Stress Reaction}

As defined in the CPG, combat and operational stress reaction (COSR) is an acute stress state that is distinct from ASR only in the social context in which it occurs - combat or other military operation - and the social requirement implicit in that context to quickly restore occupational functioning, not as the only priority for stress-injured servicemembers, but as one that must at least coexist with the imperative to prevent future psychological or behavioral illness or disability. Like ASR, COSR is conceived to be a normal and usually self-limited response to overwhelming experiences. As with ASR, the symptoms of distress and dysfunction attendant to COSR can be profound and global or they can be mild and nearly insignificant. And as with ASR, 4 days is considered the upper limit of duration for particularly severe distress or dysfunction before further evaluation and recategorization may be indicated.

\section{Acute Stress Disorder}

Unlike ASR and COSR, which are conceived to be transient and "normal," ASD is a distinct clinical entity, first incorporated into the psychiatric nosology in DSM-IV. ASD differs from ASR and COSR in that it entails clinically significant distress or impairment in social, occupational, or other important areas of functioning for longer than a brief crisis (i.e., lasting at least 2 days). At the other end of the posttraumatic stress-state spectrum, ASD differs from PTSD in its briefer duration (i.e., less than 1 month) and in its requirement for symptoms of dissociation either while or immediately after experiencing the traumatic event. Symptoms of dissociation listed in DSM-IV include a subjective sense of numbing or detachment, reduced emotional responsiveness, reduced awareness of the surroundings ("being in a daze"), derealization, depersonalization, or dissociative amnesia. In addition to these dissociative symptoms, the diagnosis of ASD requires the presence of the cardinal symptoms of PTSD, including re-experiencing, avoidance, and increased arousal. If clinically significant posttraumatic stress symptoms persist beyond 1 month, the diagnosis is changed to PTSD.

\section{Posttraumatic Stress Disorder}

PTSD is the most well-known and well-studied posttraumatic stress state, first codified as a clinical entity in the 3rd edition of the DSM, published a few years after the Vietnam war ended. The diagnosis of PTSD hinges on the presence of clinically significant distress or impairment in social, occupational, or other important areas of functioning that has persisted for at least 1 month and includes symptoms from three distinct clusters: (1) unwanted and distressing re-experiencing of traumatic memories through flashbacks, nightmares, and intrusive images or sensations; (2) avoidance of stimuli associated with the trauma and numbing of responsiveness not previously present; and (3) persistent symptoms of increased arousal, including heightened anxiety and exaggerated startle responses. PTSD may be classified as acute or chronic depending on whether its clinically significant symptoms have lasted for 3 months or longer.

\section{Guidelines for Assessment and Early Intervention}

Module A of the CPG provides specific and detailed recommendations for assessment and early intervention for persons exposed to trauma within the past 30 days whose distress and functional impairment meet criteria either for ASR/COSR, if symptoms have existed for less than 4 days, or ASD, if symptoms have lasted for at least 2 days and remain clinically significant. The overarching goals in this period are preclinical rather than clinical and entirely analogous to the goals of first aid in the aftermath of physical injury: preserve life, prevent further harm, and promote recovery. Rather than arbitrarily addressing assessment and intervention as entirely separate processes, the CPG acknowledges that in the immediate postevent period, screening for symptoms; providing basic needs; reducing concurrent threats to health and well-being; and providing targeted biological, psychological, and social interventions are iterative and interwoven processes.

The VA/DOD CPGs for the management of ASR, COSR, and ASD are based on at least three guiding assumptions. The first is that although ASRs of all types may be expectable and highly common-perhaps even universal in the context of sufficiently intense stressorsand that the great majority of persons who experience ASR or COSR recover, everyone who experiences ASR or COSR is at increased risk for PTSD and other behavioral disorders, as well as suicide, endangering others' lives, and potentially catastrophic failure of occupational 
or social functioning. The second assumption is that assessment and targeted intervention in the first 30 days can lessen the risk for PTSD and various other posttraumatic behavioral problems. The third is that while assessment and early intervention may reduce distress, improve functioning, and lessen risk for future problems, early intervention may also do harm by overly pathologizing, encouraging dependency rather than self-efficacy, and interfering with intrinsic personal or group healing processes. The CPG acknowledges that because of the paucity of existing research on the natural history and epidemiology of acute stress in either military or civilian settings and on the outcomes of early interventions of many kinds, these assumptions remain largely untested. Recommending a course of action for early intervention to promote recovery and prevent PTSD in the absence of high-quality evidence may increase the risk of doing harm rather than good, and in some cases, watchful waiting may well be the best option. The specific recommendations contained in the CPG seek the optimal balance between potential for help and risk for harm based on current available evidence.

\section{In First 4 Days: Acute Stress Reaction or Combat and Operational Stress Reaction}

Figure 3 is adapted from the first part of the CPG's Module A algorithm for the management of ASR and COSR within the first 4 days after exposure to trauma. The two sidebars, also adapted from the Module A algorithm, list many of the key elements of assessment and the meeting of immediate needs in this time period. In the CPG's discussion of its algorithm for posttraumatic stress management in the first 4 days, the following key points are emphasized.

\section{Assess Stressor Exposures}

The stressor events that trigger ASR in civilian settings and COSR during military operations share the common features of real or imagined life-threat to self or others, provoking intense physical and emotional responses and loss of control. Among civilians, traumatic events are usually experienced as isolated, unexpected events. Examples include natural disasters, accidents, and being the victim of an assault. During military operations, potentially traumatic events occur not only repeatedly over the course of a months-long deployment but in the context of the cumulative stress of many other hardships and injuries, both physical and emotional. Tools such as the Combat Exposure

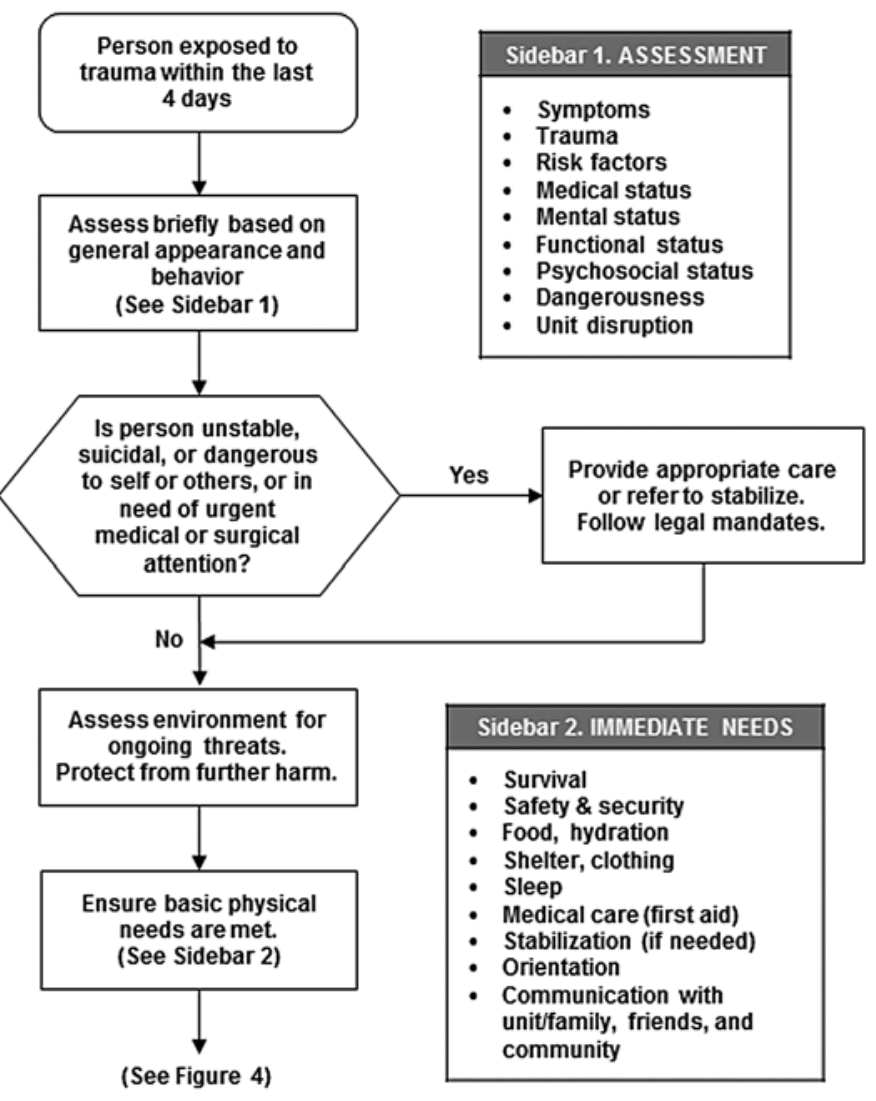

Figure 3.

First part of Clinical Practice Guideline's Module A algorithm for management of acute stress reaction (ASR) and combat and operational stress reaction (COSR) within first 4 days after exposure to trauma.

Scale [13] or Traumatic Life Events Questionnaire [14] may be helpful in getting a sense of the spectrum of exposure to traumatic stress in different contexts.

\section{Assess General Appearance and Behavior}

Although the intense distress that accompanies ASR and COSR may be internal to the traumatized person, it often manifests in externally observable alterations in appearance and behavior. Impairments of functioning in physical, emotional, cognitive, and behavioral domains are also often observable to others, especially those who are closely familiar with the stress-injured person.

\section{Assess Dangerousness and Need for Urgent Medical Attention}

Acutely stressed persons may present dangers to themselves or others because they are temporarily physically or 
mentally incapacitated, their judgment is impaired, or they are actively suicidal or harboring inappropriately aggressive impulses toward others. The risk for suicide in persons with ASR or COSR is not well studied, but the literature on suicidal ideation and aggression in subthreshold PTSD is compelling. Because ASR and COSR may occur in the context of significant physical injury-of which the injured person may not be fully aware or able to seek appropriate care for-assessment of need for urgent medical or surgical attention is important.

\section{Ensure Physical Needs Are Met}

Persons who have recently experienced traumatic stress may have significantly disrupted routines for sleep, nutrition, hygiene, and other necessities. They may also have unmet needs for information about their current status and situation and the location and welfare of others, as well as needs to communicate with family, unit members, and important others. As a "selective" intervention in the NRCIOM framework, immediate needs are assessed and met while, simultaneously, continuous assessment for ongoing threats to the welfare and safety of traumatized persons is crucial. Safety is a need of the highest priority. For example, in combat situations, a person experiencing ASRs may be informally assessed as to their mental and emotional status and immediate needs and be given 48 to 72 hours of removal from potential harm, rest, and mentoring.

\section{Provide Psychological First Aid}

Module A of the CPG introduces the key elements of psychological first aid (PFA) as a conceptual and practical framework for evidence-informed intervention in the early aftermath of traumatic stress. As the psychological or whole-person analog of physical first aid, its overarching goal is to "stop the bleeding" in the mental, emotional, social, and spiritual domains. The CPG lists the following key elements: (1) contact and engagement, (2) safety and comfort, (3) stabilization (if needed), (4) information gathering, (5) practical assistance, (6) connection with social supports, (7) information on coping, and (8) linkage to collaborative services. PFA is generally described as an "indicated" intervention in the NRC-IOM framework, to be used with those who are exhibiting stress reactions, rather than applied to the whole population or high-risk individuals who are nevertheless asymptomatic.

The CPG acknowledges that as a set of intervention procedures, PFA is neither well circumscribed nor yet well studied. Nevertheless, the evidence for the underly- ing principles of PFA is substantial and growing. Hobfoll et al. reviewed the literature on immediate and midterm interventions after mass-trauma events and found five principles to be well supported [15]. On this basis, they recommended early intervention approaches seek to promote (1) a sense of safety, (2) calming, (3) a sense of selfand community efficacy, (4) connectedness, and (5) hope. As will be described subsequently, specific intervention programs designed with these goals in mind have been well received and are increasingly being subjected to empirical study.

\section{Avoid Individual or Group Psychological Debriefing}

Psychological debriefing (PD) is a structured, singlesession, group intervention for early intervention after trauma that was first described by Mitchell in 1983 [16]. Based on the civilian crisis-intervention literature and military models for combat psychiatry, PD has been widely implemented in police, fire, emergency medicine, and military settings since its introduction. PD differs from PFA in several fundamental ways. First, PD does not include a significant component of assessment of symptom burden or needs. Rather, as a programmed group intervention, it assumes that all individuals who have experienced the same traumatic stressor have similar, if not identical, needs. Second, because PD does not include an assessment component, it is necessarily a one-size-fitsall intervention rather than a broad assortment of intervention tools and responses that can be tailored for each person's immediate status and context. Third, PD assumes that a single session of help occurring over a few hours is sufficient, without either mandated follow-up or mechanisms for assessing who needs greater help.

Several reviews of studies of the efficacy of PD have failed to find evidence that it prevents long-term negative outcomes [17-19]. Additionally, two randomized controlled trials of PD have reported a higher incidence of negative outcomes in those who received PD compared with those who did not receive any intervention [18-19]. Consequently, PD cannot be recommended as an early intervention for posttraumatic stress.

\section{For Acute Stress Disorder or Clinically Significant Symptoms Beyond First 2 Days}

Figure 4 is adapted from the second part of the CPG's Module A algorithm for the management of posttraumatic stress that persists or worsens beyond the first 2 days or that meets diagnostic criteria for ASD. In the CPG's dis- 
cussion of this portion of its algorithm, the following key points are emphasized.

\section{Identify Persons Who Have Excessive and Persistent Symptoms}

Though it may seem self-evident that interventions targeting significant and persisting symptoms are only possible if persons in need of those interventions are

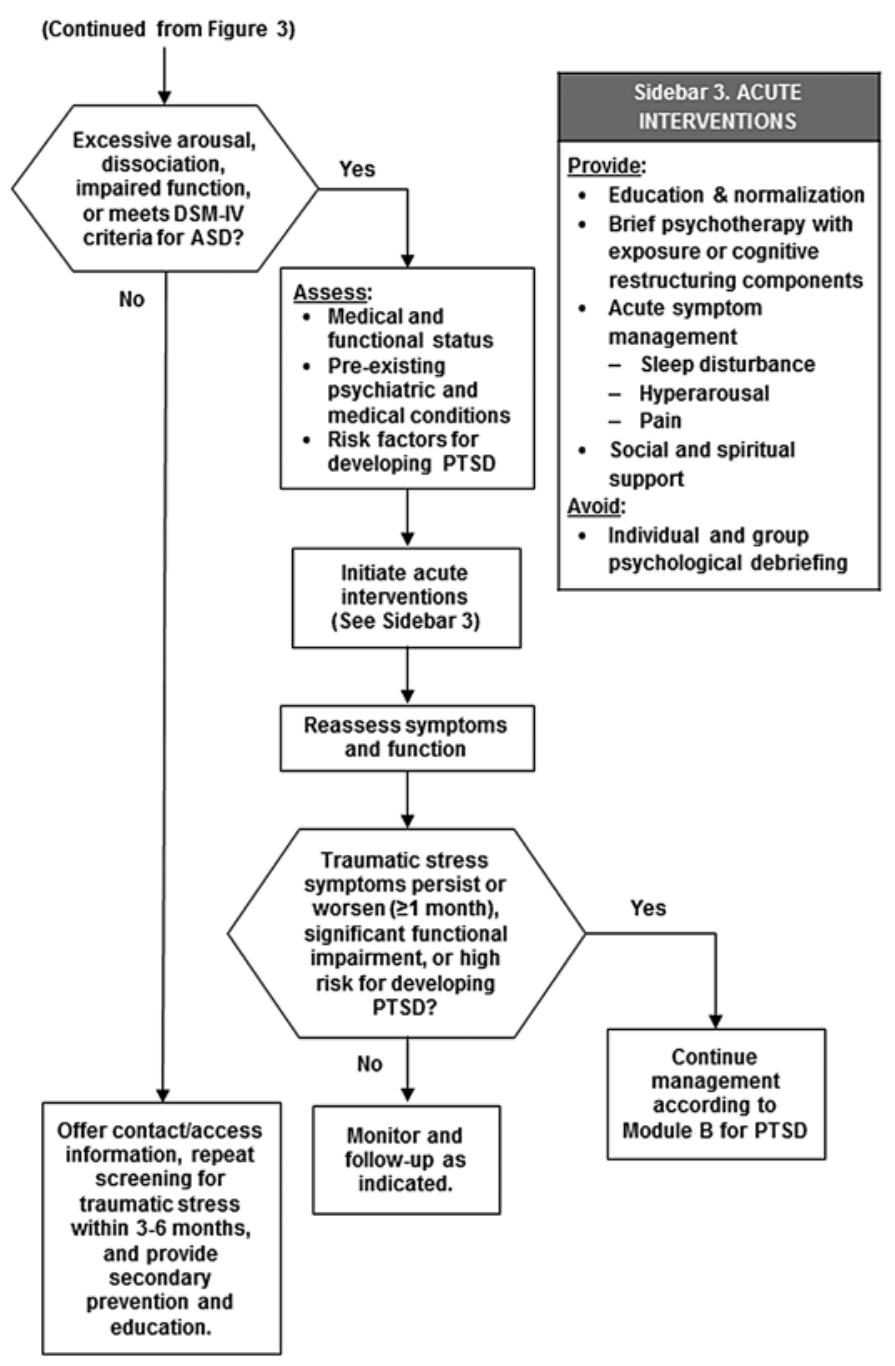

Figure 4.

Second part of Clinical Practice Guideline's Module A algorithm for management of posttraumatic stress that persists or worsens beyond first 2 days or meets diagnostic criteria for acute stress disorder (ASD). DSM-IV = Diagnostic and Statistical Manual of Mental Disorders, 4th Edition; PTSD = posttraumatic stress disorder. actively identified, this point warrants particular emphasis. Most persons who have recently experienced an overwhelming stressor experience want to put it behind them. In military settings, especially, stoicism is prized while seeking help is not and stigma erects many barriers to care and the recognition of the need for care. Persons suspected of persisting or worsening traumatic stress symptoms should be screened for ASD using DSM-IV criteria.

\section{Assess Medical and Functional Status}

If any indication exists of clinically significant distress or impairment in any area of functioning 2 days after a traumatic event, all areas of functioning should be carefully assessed, including medical status. Focal neurological deficits, positive toxicological screening, and cognitive deficits are examples of possible comorbidities that should be ruled out.

\section{Assess Pre-Existing Psychiatric and Medical Conditions}

The increased risk for PTSD caused by pre-existing psychiatric and medical conditions of various types can only be reduced if these pre-existing conditions are identified and addressed appropriately. Medication usage and availability and history of substance abuse or dependence are two examples of pre-existing medical factors that may greatly affect recovery from posttraumatic stress.

\section{Assess Risk Factors for Developing Acute Stress Disorder/ Posttraumatic Stress Disorder}

The CPG draws attention to risk factors for ASD and PTSD in three categories: (1) pretraumatic factors, (2) peritraumatic factors, and (3) posttraumatic factors. All are important to address to identify possible modifiable obstacles to recovery. An important pretraumatic factor is the cumulative stress load borne by the person at the time of the recent trauma. Physical injury or role failure due to dissociation at the time of the traumatic event are examples of significant peritraumatic factors. Many studies have identified the availability and quality of social support as highly salient posttraumatic factors.

\section{Provide Education and Normalization}

Education about the nature of traumatic stress injuries and information about effective coping strategies and options for treatment should be offered as a "selective" intervention for those in high-risk situations. 


\section{Initiate Brief Intervention}

The CPG offers evidence-based and evidenceinformed recommendations for psychological, social, and medical interventions for posttraumatic stress that persists or worsens beyond 2 days, all considered to be "indicated" interventions for those with stress reactions. The CPG gives its strongest recommendation for brief, traumafocused cognitive-behavioral therapy (CBT) delivered over 4-5 sessions as soon as persisting or worsening symptoms are recognized. Early intervention with CBT has been studied with individual survivors of motor vehicle accidents, industrial accidents, injury, and nonsexual assault who met criteria for a diagnosis of ASD. In trials delivered over the course of about 4-5 individual therapy sessions and initiated about 2 weeks after the trauma, this intervention has been significantly more effective in preventing PTSD and in decreasing depressive symptoms than simple education and support [20-21]. Persons who received the intervention tend to show a significantly lower intensity of PTSD symptoms even years after its completion [22]. The value of offering CBT as early as possible is illustrated by the finding from randomized controlled trials that similar therapy offered later than 1 month posttrauma may show less robust benefits [23-25].

The CPG concludes that social support, psychoeducation, and normalization with expectancy of recovery may be of benefit, although these are much less strongly recommended as specific interventions.

Among medications considered for use in this population, antidepressants, anticonvulsants, and atypical antipsychotics are of unknown benefit, while benzodiazepines and typical antipsychotics are recommended against because they may be of no benefit and possibly harmful. As in the management of ASR and COSR, PD is contraindicated.

\section{Manage Acute Symptoms}

The CPG separates acute symptom management from other, more trauma-focused interventions because several acute symptom clusters common in this population warrant targeted pharmacological and nonpharmacological interventions. Among these acute symptoms are sleep disturbances, pain, and excessive arousal and irritability, including panic or rage attacks. Short courses of medication (e.g., less than 6 days), relaxation training, meditation, sleep-hygiene training, and avoidance of caffeine are examples of approaches to the management of these acute symptoms. Uninterrupted sleep is crucial for recovery from posttraumatic stress.

\section{Facilitate Social and Spiritual Support}

Positive social support, particularly from trusted peers or family members, and positive spirituality may lower risk for PTSD and facilitate recovery.

\section{Monitor, Reassess, and Follow-Up}

Regardless what trajectory a given person's posttraumatic symptoms have followed, what risk or protective factors exist, or what interventions have been offered, everyone after the first 2 days postevent who has experienced clinically significant distress or functional impairment or met criteria for ASD must be considered at elevated risk for future PTSD and other behavioral disorders. Ongoing monitoring, follow-up, reassessment, and rescreening are the only way to prevent adverse outcomes.

\section{Four Current Early Interventions}

The following four existing early interventions, all founded on the concepts and actions described in the CPG, were developed by DOD and VA personnel for use both inside and outside VA and DOD settings.

\section{Psychological First Aid}

The PFA program is an evidence-informed, modular approach to helping children, adolescents, adults, and families in the immediate aftermath of disaster or terrorism, based on the broad principles of PFA [26]. Developed jointly by the National Child Traumatic Stress Network (NCTSN) and the VA's National Center for PTSD (NCPTSD), two international leaders in trauma science and practice, PFA took as its starting point the five principles for immediate and midterm recovery after natural or man-made disasters suggested by Hobfoll and colleagues’ 2007 review, cited earlier [15]. With these principles in mind, the goals of PFA are to promote safety and comfort, stabilize, attend to practical needs, enhance coping, and connect survivors with additional resources [27]. PFA includes the following eight core actions: (1) contacting and engaging individuals; (2) enhancing their safety and comfort; (3) stabilizing individuals when necessary; (4) gathering information to help guide provision of PFA actions or to refer to other services; (5) giving practical help as needed; (6) connecting people to family members, friends, and other sources of social support; (7) promoting effective coping and reducing maladaptive coping; and (8) coordinating with other services that might be needed.

As a set of actions for selective and indicated prevention, PFA is not intended for all persons in a trauma-exposed population, but rather only those individuals or subgroups 
who are either at significantly increased risk or are already experiencing significant distress or functional impairment. The core actions of PFA may be delivered by mental health professionals, non-mental health caregivers such as chaplains or emergency medical technicians, or other disaster response personnel.

While PFA has not yet been systematically studied, experience in the field and evaluation of training [28] suggests that it is well received by consumers and providers, and models are being developed for evaluation of its principles in different settings [29]. In contrast to PD, PFA takes a flexible, tailored approach to helping meet immediate physical, emotional, and social needs and it allows voluntary discussion of traumatic incidents if survivors wish, without insisting on it. Most importantly, PFA includes a strong component of assessment and reassessment to ensure that the crucial needs of each trauma survivor are met. PFA has been adapted for school staff, medical reserve corps, religious personnel, homeless youth and family shelter staff, nursing home settings, and military personnel. It has been used following disasters and terrorism across the world and has been translated into several languages.

\section{Combat and Operational Stress First Aid}

Combat and Operational Stress First Aid (COSFA) is a flexible, modular approach to indicated prevention in military units and was developed through a collaboration between the Navy, Marine Corps, and NCPTSD by modifying PFA for use in the military and other organizations having pre-existing social structures that include clearly defined leadership, cohesive subunits with high levels of social engagement, and a network of available support [11]. Recognizing that peers and leaders are always the "first responders" in military operational settings, COSFA incorporates the language and principles taught to Navy and Marine Corps leaders for combat and operational stress control more broadly [30].

COSFA includes the following seven actions: (1) Check: assess and reassess; (2) Coordinate: inform others and refer if needed; (3) Cover: get to safety and keep safe; (4) Calm: reduce physiological and emotional arousal; (5) Connect: restore social support from peers and family; (6) Competence: restore personal, occupational, and social self-efficacy; and (7) Confidence: restore self-esteem and hope. The first two COSFA actions - Check and Coordinate- are considered universal functions of leaders, peers, and family members to be performed frequently and continuously, not merely after potentially traumatic events or losses.
The second two COSFA actions - Cover and Calm-are crisis-intervention tools that may be needed infrequently and only briefly, but when they are needed because of a serious ASR or COSR, they are needed immediately. The final three COSFA actions-Connect, Competence, and Confidence-focus on the long haul, well beyond shortterm crisis situations, to promote recovery and well-being.

COSFA outcomes have not yet been empirically evaluated. However, training programs in COSFA have been well received by chaplains and line leaders in several military service branches, both Active Duty and National Guard. A controlled study is currently underway to assess the outcomes of the Marine Corps' OSCAR (Operational Stress Control and Readiness) program, which delivers training in COSFA basics to squad leaders in Marine ground combat units.

\section{Skills for Psychological Recovery}

Skills for Psychological Recovery (SPR) was developed by the NCPTSD and NCTSN as a skills-based intervention to assist individuals with moderate levels of distress in the weeks and months postdisaster. It is evidence-based, yet flexible and modular, and can be implemented by paraprofessionals [31]. The skills included in SPR (designed to be stand-alone modules if necessary) are problem solving, positive activity scheduling, managing reactions, promoting helpful thinking, and rebuilding healthy social connections. SPR has been introduced into several postdisaster crisis counseling programs in the United States and Australia, with evaluation reports indicating that it significantly reduced distress and decrements in functioning and was favorably perceived by providers as an acceptable and useful intervention [32-33].

\section{Families Overcoming Under Stress}

Families Overcoming Under Stress (FOCUS) is an evidence-informed, family-centered resiliency training program for military and veteran families facing or recovering from deployment stress [34]. Developed collaboratively by University of California, Los Angeles, and Harvard Medical School, FOCUS includes a suite of customizable approaches for servicemembers, spouses, and children of all ages. Its core family intervention is a manualized, eight-session, strength-based training to promote selective and indicated prevention in entire families. Its components include psychoeducation, mapping of deployment timelines, family communication skills, goal setting and problem solving, emotional regulation skills, and management of trauma and loss reminders. 
Since 2008, the Navy Bureau of Medicine has implemented FOCUS across 18 military installations worldwide, and five additional sites have been launched in DOD. FOCUS has also been modified for use with couples and families with war-wounded servicemembers. Initial outcome data for FOCUS interventions with more than 4,000 adults and children are significantly positive [35].

\section{DISCUSSION}

The revised VA/DOD CPG for Management of PostTraumatic Stress includes a robust set of evidence-based and evidence-informed recommendations to promote the prevention of PTSD, including thorough screening and early interventions for precursor stress states such as ASR, COSR, and ASD. During the first 4 days after a potentially traumatic event, priorities for management include ensuring safety; attending to basic needs; and ensuring access to necessary physical, emotional, and social resources. PFA, as the mental, emotional, social, and spiritual analog of physical first aid, is the recommended approach to management for ASR and COSR. PD is discouraged as it is not proven effective and is possibly harmful. If clinically significant distress or impairment in social, occupational, or other areas of functioning persist or worsen after 2 days or if the criteria for a diagnosis of ASD are met, further medical and psychiatric assessment is warranted and management strategies shift toward the provision of brief, trauma-focused CBT. Acute symptoms such as insomnia and hyperarousal should be managed through brief medication regimens and self-calming techniques. Since everyone who experiences ASR, COSR, or ASD in the aftermath of a potentially traumatic event is at elevated risk for PTSD, regardless of short-term symptom course, follow-up monitoring and rescreening should occur for at least 6 months. PFA, COSFA, SPR, and FOCUS are four successful programs currently underway in DOD and the VA that illustrate the principles contained in the VA/DOD CPG for the prevention of PTSD.

\section{CONCLUSIONS}

While the CPG offers guidance based on the best available evidence and existing programs based on the CPG have experienced early success, there is still a great need for research that will evaluate the effectiveness of early interventions with Active Duty and veteran populations, who are often in situations of ongoing threat and cumulative stress from loss, inner conflict, traumatic exposure, and wear and tear. Additionally, many are not open to help, do not believe that they need help, believe that acknowledgment of distress is an indication of weakness, or will only seek informal support from family and friends early on. Therefore, the early interventions recommended in the CPG need to be tested in different settings and for a variety of outcomes and the preferences of recipients should always be considered when implementing them.

\section{ACKNOWLEDGMENTS}

Author Contributions:

Drafting of manuscript: W. P. Nash, P. J. Watson.

Financial Disclosures: The authors have declared that no competing interests exist.

Funding/Support: This material was unfunded at the time of manuscript preparation.

\section{REFERENCES}

1. Management of Post-Traumatic Stress Working Group [Internet]. VA/DOD clinical practice guideline for management of post-traumatic stress. Washington (DC): Department of Veterans Affairs, Department of Defense; 2010. Available from: http://www.healthquality.va.gov/ptsd/ptsd full.pdf

2. Department of Defense Task Force on Mental Health. An achievable vision: report of the Department of Defense Task Force on Mental Health. Falls Church (VA): Defense Health Board; 2007.

3. Tanielian T, Jaycox LH, editors. Invisible wounds of war: psychological and cognitive injuries, their consequences, and services to assist recovery. Santa Monica (CA): RAND Corporation; 2008.

4. Weinick RM, Beckjold EB, Farmer CM, Martin LT, Gillen EM, Acosta J, Fisher MP, Garnett J, Gonzalez GC, Helmus TC, Jaycox LH, Reynolds K, Salcedo N, Scharf DM. Programs addressing psychological health and traumatic brain injury among U.S. servicemembers and their families. Santa Monica (CA): RAND Corporation; 2011.

5. Jonas WB, O’Connor FG, Deuster P, Peck J, Shake C, Frost SS. Why total force fitness? Mil Med. 2010;175:6-13.

6. Cornum R, Matthews MD, Seligman ME. Comprehensive soldier fitness: building resilience in a challenging institutional context. Am Psychol. 2011;66(1):4-9. [PMID:21219042] http://dx.doi.org/10.1037/a0021420 
7. Nash WP, Steenkamp M, Conoscenti L, Litz BT. The stress continuum model: a military organizational approach to resilience and recovery. In: Southwick SM, Litz BT, Charney D, Friedman M, editors. Resilience and mental health: challenges across the lifespan. Cambridge (UK): Cambridge University Press; 2011. p. 238-52.

8. Gordon RS Jr. An operational classification of disease prevention. Public Health Rep. 1983;98(2):107-9.

[PMID:6856733]

9. Institute of Medicine. Reducing risks for mental disorders: frontiers for prevention intervention science. Washington (DC): National Academies Press; 1994.

10. National Research Council, Institute of Medicine. Preventing mental, emotional, and behavioral disorders among young people: progress and possibilities. Washington (DC): National Academies Press; 2009.

11. Nash WP, Krantz L, Stein N, Westphal RJ, Litz BT. Comprehensive soldier fitness, battlemind, and the stress continuum model: military organizational approaches to prevention. In: Ruzek J, Vasterling J, Shnurr P, Friedman M, editors. Caring for veterans with deployment-related stress disorders: Iraq, Afghanistan, and beyond. Washington (DC): American Psychological Association; 2011.

12. Nash WP, Vasterling J, Ewing-Cobbs L, Horn S, Gaskin T, Golden J, Riley WT, Bowles SV, Favret J, Lester P, Koffman R, Farnsworth LC, Baker DG. Consensus recommendations for common data elements for operational stress research and surveillance: report of a federal interagency working group. Arch Phys Med Rehabil. 2010; 91(11):1673-83.

[PMID:21044711]

http://dx.doi.org/10.1016/j.apmr.2010.06.035

13. Keane T, Fairbank J, Caddell J, Zimering R, Taylor K, Mora C. Clinical evaluation of a measure to assess combat exposure. Psychol Assess. 1989;1(1):53-55. http://dx.doi.org/10.1037/1040-3590.1.1.53

14. Kubany ES, Haynes SN, Leisen MB, Owens JA, Kaplan AS, Watson SB, Burns K. Development and preliminary validation of a brief broad-spectrum measure of trauma exposure: the Traumatic Life Events Questionnaire. Psychol Assess. 2000;12(2):210-24. [PMID:10887767] http://dx.doi.org/10.1037/1040-3590.12.2.210

15. Hobfoll SE, Watson PJ, Bell CC, Bryant RA, Brymer MJ, Friedman MJ, Friedman M, Gersons BP, de Jong JT, Layne CM, Maguen S, Neria Y, Norwood AE, Pynoos RS, Reissman D, Ruzek JI, Shalev AY, Solomon Z, Steinberg AM, Ursano RJ. Five essential elements of immediate and mid-term mass trauma intervention: empirical evidence. Psychiatry. 2007; 70(4):283-315, discussion 316-69. [PMID:18181708] http://dx.doi.org/10.1521/psyc.2007.70.4.283

16. Mitchell JT. When disaster strikes...the critical incident stress debriefing process. JEMS. 1983;8(1):36-39.

[PMID:10258348]
17. Litz BT, Maguen S. Early intervention for trauma. In: Friedman MJ, Keane TM, Resick PA, editors. Handbook of PTSD: science and practice. New York (NY): Guilford Press; 2007. p. 306-29.

18. McNally RJ, Bryant RA, Ehlers A. Does early psychological intervention promote recovery from posttraumatic stress? Psychol Sci Public Interest. 2003;4:45-79.

19. Rose S, Bisson JI, Wessely SC. A systematic review of single-session psychological interventions ('debriefing') following trauma. Psychother Psychosom. 2003;72(4):176-84. [PMID:12792122]

http://dx.doi.org/10.1159/000070781

20. Bryant RA, Harvey AG, Dang ST, Sackville T, Basten C. Treatment of acute stress disorder: a comparison of cognitive-behavioral therapy and supportive counseling. J Consult Clin Psychol. 1998;66(5):862-66. [PMID:9803707] http://dx.doi.org/10.1037/0022-006X.66.5.862

21. Bryant RA, Sackville T, Dang ST, Moulds M, Guthrie R. Treating acute stress disorder: an evaluation of cognitive behavior therapy and supportive counseling techniques. Am J Psychiatry. 1999;156(11):1780-86.

[PMID:10553743]

22. Bryant RA, Moulds ML, Nixon RV. Cognitive behaviour therapy of acute stress disorder: a four-year follow-up. Behav Res Ther. 2003;41(4):489-94. [PMID:12643970] http://dx.doi.org/10.1016/S0005-7967(02)00179-1

23. Bisson JI, Shepherd JP, Joy D, Probert R, Newcombe RG. Early cognitive-behavioural therapy for post-traumatic stress symptoms after physical injury. Randomised controlled trial. Br J Psychiatry. 2004;184:63-69. [PMID:14702229] http://dx.doi.org/10.1192/bjp.184.1.63

24. Zatzick D, Roy-Byrne P, Russo J, Rivara F, Droesch R, Wagner A, Dunn C, Jurkovich G, Uehara E, Katon W. A randomized effectiveness trial of stepped collaborative care for acutely injured trauma survivors. Arch Gen Psychiatry. 2004;61(5):498-506. [PMID:15123495] http://dx.doi.org/10.1001/archpsyc.61.5.498

25. Foa EB, Zoellner LA, Feeny NC. An evaluation of three brief programs for facilitating recovery after assault. J Trauma Stress. 2006;19(1):29-43. [PMID:16568461] http://dx.doi.org/10.1002/jts.20096

26. Brymer M, Jacobs A, Layne C, Pynoos R, Ruzek J, Steinberg A, Vemberg E, Watson P. (National Child Traumatic Stress Network and National Center for PTSD). Psychological first aid: field operations guide, 2nd ed. [Internet]; National Child Traumatic Stress Network and National Center for PTSD; 2006 Jul. Available from: http://www.nctsn.org, http://www.ncptsd.va.gov

27. Brymer MJ, Steinberg AM, Watson PJ, Pynoos RS. Prevention and early intervention programs for children and adolescents. In: Beck JG, Sloan D, editors. The Oxford 
handbook of traumatic stress disorders. New York (NY): Oxford University Press; 2012.

28. Allen B, Brymer MJ, Steinberg AM, Vernberg EM, Jacobs A, Speier AH, Pynoos RS. Perceptions of psychological first aid among providers responding to Hurricanes Gustav and Ike. J Trauma Stress. 2010;23(4):509-13.

[PMID:20623598] http://dx.doi.org/10.1002/jts.20539

29. Forbes D, Lewis V, Varker T, Phelps A, O’Donnell M, Wade DJ, Ruzek JI, Watson P, Bryant RA, Creamer M. Psychological first aid following trauma: implementation and evaluation framework for high-risk organizations. Psychiatry. 2011;74(3):224-39. [PMID:21916629] http://dx.doi.org/10.1521/psyc.2011.74.3.224

30. Nash WP. Marine Corps and Navy combat and operational stress continuum model: a tool for leaders. In: Ritchie EC, editor. Combat and operational behavioral health. Fort Detrick (MD): Borden Institute; 2011. p. 107-19.

31. Berkowitz S, Bryant R, Brymer M, Hamblen J, Jacobs A, Layne C. Skills for psychological recovery: field operations guide. Washington (DC): National Center for PTSD (U.S. Department of Veterans Affairs) and National Child Traumatic Stress Network (funded by U.S. Department of Health and Human Services and jointly coordinated by University of California, Los Angeles, and Duke University); 2010.

32. Forbes D, Fletcher S, Wolfgang B, Varker T, Creamer M, Brymer MJ, Ruzek JI, Watson P, Bryant RA. Practitioner perceptions of Skills for psychological recovery: a training programme for health practitioners in the aftermath of the Victorian bushfires. Aust N Z J Psychiatry. 2010; 44(12):1105-11. [PMID:21070106] http://dx.doi.org/10.3109/00048674.2010.513674
33. Hansel TC, Osofsky HJ, Steinberg AM, Brymer MJ, Landis R, Riise KS, Gilkey S, Osofsky JD, Speier A. Louisiana Spirit Specialized Crisis Counseling: counselor perceptions of training and services. Psychol Trauma. 2011;3(3):276-82. http://dx.doi.org/10.1037/a0024644

34. Lester P, Mogil C, Saltzman W, Woodward K, Nash W, Leskin G, Bursch B, Green S, Pynoos R, Beardslee W. Families overcoming under stress: implementing family-centered prevention for military families facing wartime deployments and combat operational stress. Mil Med. 2011;176(1):19-25. [PMID:21305955]

35. Lester P, Saltzman WR, Woodward K, Glover D, Leskin GA, Bursch B, Pynoos R, Beardslee W. Evaluation of a family-centered prevention intervention for military children and families facing wartime deployments. Am J Public Health. 2012;102(Suppl 1):S48-54. [PMID:22033756] http://dx.doi.org/10.2105/AJPH.2010.300088

Submitted for publication October 18, 2011. Accepted in revised form January 9, 2012.

This article and any supplementary material should be cited as follows:

Nash WP, Watson PJ. Review of VA/DOD Clinical Practice Guideline on management of acute stress and interventions to prevent posttraumatic stress disorder. J Rehabil Res Dev. 2012;49(5):637-48. http://dx.doi.org/10.1682/JRRD.2011.10.0194

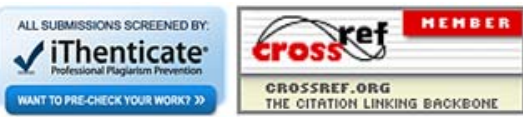

